\title{
Optimal Allocation of FACTS Devices in Restructured Power Systems Integrated Wind Generation
}

\author{
التخصيص الامثل لاجهزة نقل التيار المتردد المرنة فى نظم القوى معادة

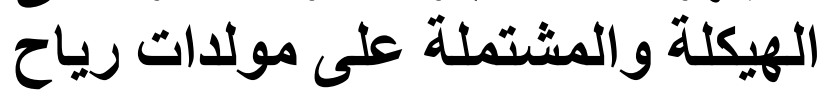

\author{
A. Eladl, A. Elmitwally, S. Eskander and I. Mansy \\ Electrical Engineering Department, Mansoura University, Mansoura 35516, \\ Egypt
}

يقترح هذا البحث طريقة لتحديد الامكان المثلى وقدرات أجهزة نظم نقل التيار المتردد المرنة (FACTS Devices)

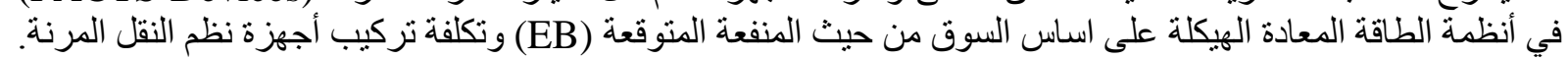

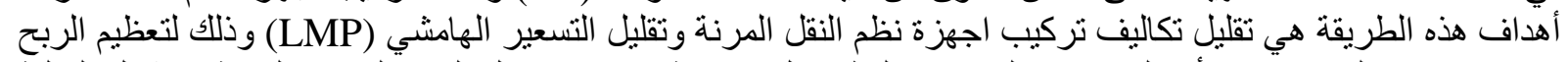

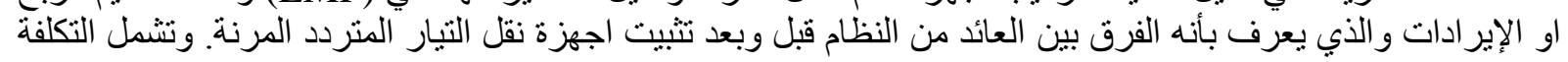

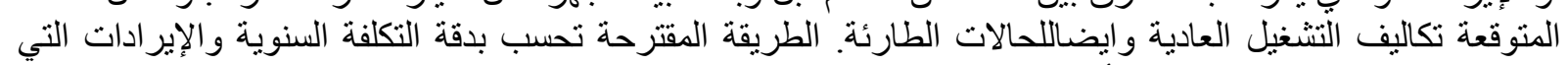

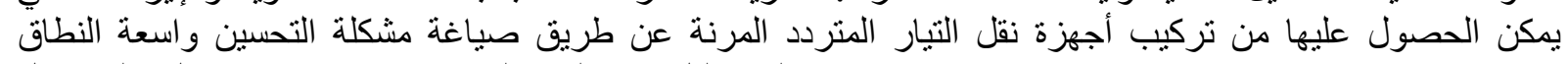
(large-scale optimization problem)

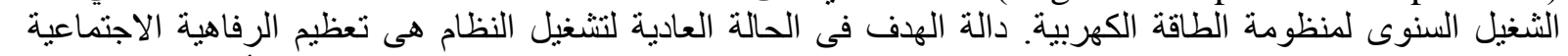
(social welfare)

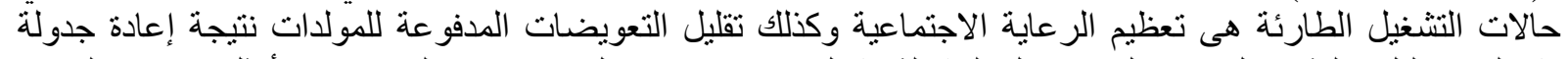

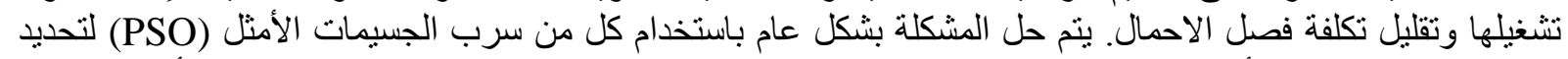
افضل امكان وقدر ات لأجهزة نقل التيار المتردد المرنة وتمثل المشكلة الرئيسية واستخدام تدفق القدرة الأمثل (OPF)

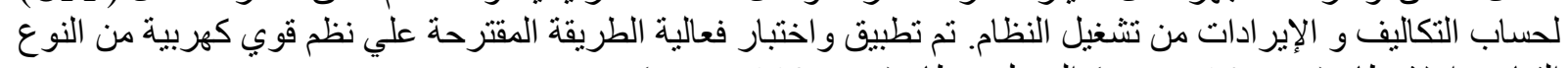
القياسي اولا نظام (IEEE 14-Bus) المعدل ونظام (IEEE 118-Bus).

\begin{abstract}
This paper proposes an approach to optimally allocate flexible AC transmission system (FACTS) devices in market-based restructured power systems based on Expected Benefit (EB) and installation cost of FACTS devices (FDs). The aims of the approach are minimizing device investment cost, and the locational marginal pricing (LMP) differences between buses to maximize revenue. This revenue is defined as the difference between EB with and without FACTS installation. The expected cost includes operating cost not only under normal condition but also under contingencies along with their associated probabilities to occur. The proposed method accurately evaluates the annual cost and benefits obtainable by FACTS devices installation by formulating a large-scale optimization problem that contains power flow analyses for a large number of system states representing annual power system operations. The objectives for normal state are maximizing social welfare by minimizing LMPs differences between buses and minimizing of generations re-scheduling, while the objectives in case of contingency are maximizing social welfare as well as minimizing compensations paid for generations re-scheduling and load shedding cost. The overall problem is solved using both Particle Swarm optimization (PSO) for attaining optimal FACTS devices setting and allocation as main problem and optimal power flow to calculate the operating costs and benefits as sub optimization problem. The effectiveness of the proposed approach is demonstrated on modified IEEE 14-bus test system and IEEE 118-bus test system.
\end{abstract}

\section{Keywords}

Optimal Allocation of FACTS Devices, Congestion management, expected security cost, voltage stability, OPF, LMP, PSO, FACTS Devices Investment recovery. 


\section{Nomenclature}
$\boldsymbol{B}, \boldsymbol{C}$ Consumer benefit and generation cost respectively.
$\boldsymbol{D}, \boldsymbol{G}$ Set of demands and generators, respectively.
$\boldsymbol{i}, \boldsymbol{j} \quad$ Bus indices.
$\mathbf{k} \quad$ Symbol indicating under contingency state.
Scalar variable used to represent

Ks $\quad$ system losses related to the stressed loading condition.
M Set of locations candidate for
$M \quad$ TCSC.

$N \quad$ Set of locations candidate for SVC.

$\boldsymbol{r} \quad$ The bilateral transaction index;

o Symbol indicating under normal

state.

$\boldsymbol{t} \quad$ Load level

$\boldsymbol{U}$ Set of locations candidate for

$U$ UPFC.
$\boldsymbol{B}_{\text {SVC }}$ The susceptance of the SVC at the voltage of 1 p.u.

$c_{1 x}, \quad$ Installed capacity at location $\chi$. The maximum installed capacity of

$c_{1 x, \max }$ FACTS device candidate at location $\chi$.
$C^{k} \quad$ Operating cost under contingency
c state.
$C^{o} \quad$ Operating cost under normal state.

$\boldsymbol{C}_{\boldsymbol{L} S} \quad$ Compensation paid to demand for

decreasing active power.

$C_{S V C}$ SVC investment cost per KVAr-

$C_{\text {TCSC }}$ TCSC investment cost per KVArinstalled.

$\boldsymbol{C}_{U P F C}$ UPFC investment cost per KVAr-

installed.

$\boldsymbol{C}_{\boldsymbol{w} \boldsymbol{i}} \quad$ The wind power generation cost.

$\boldsymbol{C}_{G D}^{u p}$ Compensation paid to generator for increasing active power.

$C_{G D}^{\text {down }}$ Compensation paid to generator for decreasing active power.

$\boldsymbol{I C}_{\boldsymbol{d e v}}$ Investment cost of FDs.

$I_{G} \quad$ The set of injection buses for
$J_{D} \quad$ The set of extraction buses for bilateral transaction.

$N_{g} \quad$ The set of pool and multilateral generators.

$N_{L} \quad$ The set of pool and multilateral loads.

$N_{W} \quad$ The set of wind power generation units.

$\boldsymbol{P}_{\boldsymbol{G}} \quad$ Active power generation.

$\boldsymbol{P}_{\boldsymbol{D}}, \boldsymbol{Q}_{\boldsymbol{D}}$ The active and reactive pool power demand, respectively.

$\begin{array}{ll}\boldsymbol{P}_{G r, i} & \text { The real power for multilateral } \\ \text { injection of agent } R \text { at bus } i .\end{array}$

$\boldsymbol{P}_{D r, i}$ The real power for multilateral extraction of agent $R$ at bus $i$.

$\boldsymbol{P}_{\boldsymbol{w i}} \quad$ The power generated by wind

generator at bus $i$.

$\boldsymbol{Q}_{\boldsymbol{G r}, \boldsymbol{i}}$ The reactive power for multilateral

Q injection of agent $R$ at bus $i$.

$\boldsymbol{Q}_{\boldsymbol{D r}, \boldsymbol{i}} \quad$ The reactive power for multilateral

extraction of agent $R$ at bus $i$.

$\boldsymbol{S}_{\boldsymbol{S V C}} \quad$ SVC capacities in MVAr.

$\boldsymbol{S}_{\text {TCSC }}$ TCSC capacities in MVAr.

$\boldsymbol{S}_{\boldsymbol{U} \text { PFC }}$ UPFC capacities in MVAr

$\boldsymbol{X}_{\text {line }}$ the reactance of the transmission

$X_{\text {line }} \quad$ line between bus $i$ and $j$

$\boldsymbol{X}_{\text {TCSC }}$ The reactance contributed by TCSC

$\boldsymbol{r}_{\text {TCSC }}$ The degree of compensation of

TCSC.

$\Delta \boldsymbol{P}_{\boldsymbol{g}} \quad$ Generation re-scheduling vector $(\triangle P g=0$ at normal state).

$\Delta \boldsymbol{P}_{\boldsymbol{d}} \quad$ Load shedding vector $\left(\Delta P_{d}=0\right.$ at normal state).

$\Delta \boldsymbol{P}_{\boldsymbol{G}}^{\boldsymbol{u} \boldsymbol{p}}$ Active power generation adjustment up.

$\Delta \boldsymbol{P}_{G}^{\text {down }}$ Active power generation adjustment down. $\Delta \boldsymbol{P}_{\boldsymbol{D}}^{\text {down }}$ Active power demand adjustment

Load margin ( $\lambda=0$ at current loading condition).

Symbol indicating under stressed loading condition. 


\section{Introduction}

The reconstructed power systems are confronted with new challenges to build new transmission lines (TLs) for accommodating significantly increased power transactions. Where, the rapid technological progress causes the consumption of electric energy increases continuously. But the transmission systems are not extended to the same extent because building of new lines is difficult for environmental as well as political reasons. Hence, the systems are driven closer to their limits resulting in congestions and critical situations endangering the system security [1].

When the TLs become congested, meaning that no additional power can be transferred from a point of injection to a point of extraction, more expensive generating units may have to be brought on-line on one side of the transmission system. In a competitive market, such an occurrence would cause different locational marginal prices (LMPs) between the two locations. If transmission losses are ignored, a difference in LMPs would appear when lines are congested. Conversely, if flows are within limits (no congestion), LMPs will be the same at all buses and no congestion charges would apply. The difference in LMPs between the two ends of a congested TL is related to the extent of congestion and MW losses on this line [2]. Therefore, in a restructured electricity market, the congestion and losses of TLs should be treated by independent system operators (ISOs) to maximize social welfare while maintaining the system security. To achieve such secure and economic operation, means such as flexible ac transmission system (FACTS) devices are effective when installed in proper location with suitable setting. Then, if congestion still exists after performing this action, generation re-scheduling and load shedding would be carried out [3].

FDs can be connected to a TL in various ways, such as in series, shunt, or a combination of series and shunt. The static
VAR compensator (SVC) and static synchronous compensator (STATCOM) are connected in shunt. The static synchronous series compensator (SSSC) and thyristor controlled series capacitor (TCSC) are connected in series. Unsimilarly, the thyristor controlled phase shifting transformer (TCPST) and unified power flow controller (UPFC) are connected in series and shunt combination. The terms and definitions of various FDs are described in reference [4]. It has been proved that the steady state power transfer capability of a TL can be doubled when a FACTS is placed at midpoint of the line. Compensation by FACTS enhances the real power handling capacity of a line at a much lower cost than building a second TL of the same capacity. FDs accomplish smooth control of power over a wide range to support the TL [5].

FDs have to be located and sized properly to be effective [3]. The techniques used for optimal placement of FDs can be broadly classified into two methods:

i) Index-based method: the priority list is formed to reduce solutions space based on sensitivity indexes or tangent vector technique to determine sensitivity factor for each line and bus to ranking the optimal placement of FDs [6-10].

ii) Optimization-based method: use either conventional methods or heuristic methods. In recent years, the intelligent optimization techniques, such as simulated annealing (SA), the genetic algorithm (GA), Tabu search (TS), and particle swarm optimization (PSO), have received more attention [11-16].

The type of the associated power system analysis depends upon the objective function to be achieved; the power flow (PF) analysis is used to obtain the bus voltage and the power flow in the line, while the optimal PF (OPF) is used to obtain generation scheduling, load shedding and LMP etc. The Continuation Power Flow (CPF) is used to determine the maximum loadability of the system or 
evaluation of maximum available transfer capability (ATC) [17].The objective function can be single or multi-objective operating cost, maximizing the load benefit, minimizing the TL losses, maximizing the transmission system loadability, minimizing the cost of FACTS, and minimizing the voltage deviation at buses, etc [18].

Many recent studies have focused on FDs allocation considering voltage stability and congestion relief. References [6] and [7] have proposed optimal allocation methods for TCSC to eliminate the line overloads against contingencies, where sensitivity index called single contingency sensitivity (SCS) is introduced for ranking the optimal placement. In [8], an index developed by reactive power spot price has been used for optimal allocation of SVC. Priority list method based on the LMPs in the security constrained OPF is used in [9] to reduce solutions space for TCSC allocation for congestion management. The LMP based market is gaining popularity in recent years and is the preferred way of pricing energy and managing congestion in many deregulated electricity markets. Reference [10] has proposed a technique to recover the investment cost of TCSC for congestion management in deregulated electricity markets. The proposal evaluates the benefits of TCSC and converts them into monetary values. It is based on increase in generator and load surplus due to use of TCSC. In [11], the FACTS location problem is solved by means of genetic algorithms to lower the cost of energy production and to improve the system loading margin, respectively. In [12], the FACTS location problem is formulated as a mixed-integer nonlinear programming problem. The optimal placement is obtained by optimizing both the investment cost in FACTS and the security in terms of the cost of operation under contingency events. The problem is considered convex and solved by Benders decomposition. Reference [13] has proposed an improved solution using the multi-start Benders decomposition optimizing certain technical/economic operational goals, such as minimizing the

technique to maximize the loading margin of a transmission network through the placement of SVCs. In [14], an extended formulation is proposed, where metaheuristic technique is used to avoid difficulties in solving non-convexity problem.

In [15], PSO technique is presented to seek the optimal places of TCSC, SVC and UPFC in power system. The objectives of optimization are minimizing the cost of FACTS installation and improving the system loadability. It is obvious from the achieved results that the system loadability cannot be enhanced further after locating specific number of FDs. The maximum loadability of system is obtained by UPFC with higher cost of installation. However, economic feasibility analysis is not included in that paper. In [16], a metaheuristic technique such as Non-dominated sorting particle swarm optimization (NSPSO) has been used to find optimal locations of FDs in order to maximize static voltage stability margin (SVSM) or loading margin, reduce real power losses (RPL), and reduce load voltage deviation (LVD) to improve system loadability.

Almost all of the reported methods have not explicitly taken into account both the normal state and contingency state operation analysis in the FACTS allocation problem. Also, the compensations for generations re-scheduling are not addressed at various operating conditions. Furthermore, the appropriate market model is mostly missing. This paper proposes a new approach for optimal allocation of FDs in restructured power system integrating wind generation. The objective is to maximize the annual profit under both normal and contingency operation, meanwhile maintaining system stability and security. This implies to minimize devices investment cost, minimize the LMPs difference between buses, and maximize benefit due to devices installation. The 
problem is formulated as a large-scale optimization problem. In addition, dynamic state transitions caused by specified contingencies are also included in the optimization problem. Several load and wind generation levels representing distinctive conditions are used in the analysis. The formulated optimization problem is highly nonlinear and mixed integer problem. PSO is utilized for determining FDs locations and capacities, while OPF-based optimization is used to determine operating cost. Modified IEEE 14-bus and IEEE 118-bus systems are used to verify the effectiveness of proposed method.

\section{Facts model}

For static applications, FDs can be modeled by two methods: (i) Power Injection Model (PIM), (ii) Impedance Insertion Model (IIM). The power injection model describes the FACTS as a device that injects a certain amount of active and reactive power to a node, so that the FDs are represented as PQ elements. The impedance insertion model represents the FDs as known impedance inserted to the system in series, shunt or combination of them according to the type of FD. These methods do not destroy the symmetrical characteristic of the admittance matrix and allows efficient and convenient integration of FDs into existing power system analytical software tools $[9,10]$.

This paper focuses on the optimal locations and settings of three kinds of FACTS, namely the SVC, TCSC, and the UPFC. Among FDs, TCSC, SVC and the UPFC are chosen because of their fast control responses, low investment costs and ability to efficiently increase loadability as discussed in [11] and [19].

\subsection{Model of SVC}

The SVC is a shunt compensator that may have two modes: inductive or capacitive. In the first case, it absorbs reactive power while in the second one the reactive power is injected [11]. The SVC combines a capacitor bank shunted by Thyristor controlled reactor as shown in Fig. 1a. In this paper, the SVC is modeled as a variable admittance as in Fig.1b.

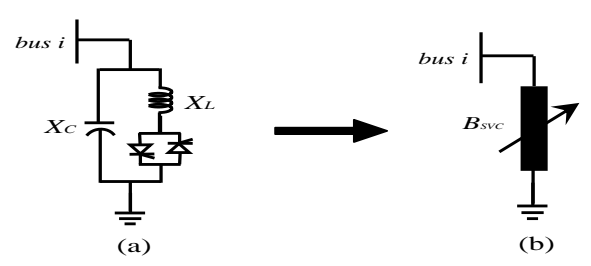

Fig. 1 Static var compensator (a) basic structure, (b) model

The reactive power provided is limited and given by:

$S_{S V C}=-V_{i}^{2} \times B_{S V C}$
and $\quad B_{S V C \text { min }} \leq B_{S V C} \leq B_{S V C \text { max }}$

\subsection{Model of TCSC}

The TCSC is a series compensation component which consists of a series capacitor bank shunted by Thyristor controlled reactor as in Fig. 2a.

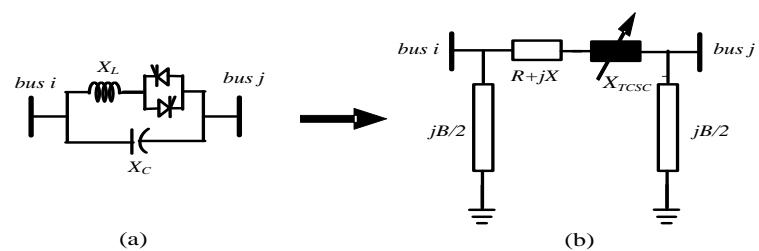

Fig. 2. Thyristor controlled series compensator (a) basic structure, (b) model.

The basic idea behind power flow control with the TCSC is to vary the overall line's effective series impedance, by adding a capacitive or inductive impedance $[16,20]$. The TCSC is modeled as variable impedance as depicted in Fig. 2b. After installing TCSC, the new reactance of the line is estimated as:

$X_{i j}=X_{\text {line }}+X_{T C S C}=r_{T C S C} . X_{\text {line }}$

To avoid overcompensation, the working range of TCSC is set between $-0.7 X_{\text {line }}$ (capacitive) and $0.2 X_{\text {line }}$ (inductive) [20].

\subsection{Model of UPFC}

Basically, the UPFC consists of series and shunt voltage source inverters. These two inverters share a common DC-link. They are connected to the power system through 
two coupling transformers. The basic structure of UPFC is shown in Fig.3.

The UPFC can control the voltage, impedance, phase angle, real and reactive power flow in a TL. The voltage drop on the line can be regulated by the shunt converter of UPFC and the power flow is controlled by the series converter [21].

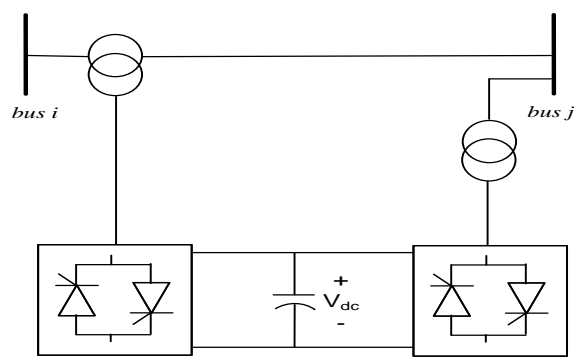

Fig. 3 The basic structure of UPFC.

The UPFC can have a Coupled model or a Decoupled model. For the Coupled model, UPFC is modeled as two series combinations of a voltage source and an impedance. One of them is series connected to the line. The second is shunt connected to the TL. The two combinations are coupled through the UPFC control system. For the Decoupled model, the above two voltage source-impedance combinations are independent [22].The first model is more complex compared to the second one because modification of Jacobian matrix in coupled model is inevitable [21]. Unsimilarly, decoupled model can be easily implemented in conventional power flow algorithms without modification of Jacobian matrix elements. In this paper, decoupled model has been used for modeling UPFC in OPF study. The characteristics of the elements used to represent this device are the same as above for the TCSC, and the SVC.

\section{Problem formulation}

The problem is composed of two levels, the FDs setting and location sub-problem (upper level) and operation sub-problem (lower level).The problem includes both normal and contingency states. The upper level sub-problem is to determine locations and capacities of FDs. The latter is an OPFbased problem to obtain minimum operating cost of each state incorporating FDs given by the upper level. Then, the operating costs, as a component of the total annual cost, are fed back to the upper level. The iterative process is repeated until a termination criterion is satisfied. In practical power system, the load grows in each year by a certain percentage. In this paper, the annual load growth rate is taken as a fixed value of 5\%. Typically, yearly load pattern is clustered into several load levels. Three fixed power load levels, $100 \%, 75 \%$, and $50 \%$ of yearly base load, are used in simulations. The first level represents peak load condition during which congestion is likely to occur not only during contingency but also during normal state. The second level corresponds to average load level in which congestion is likely to occur only during contingency. For the third level, there is a slight possibility that congestion occurs during both normal and contingency states.

Many modern utilities in Europe have considerable penetration levels of renewable resources, particularly wind energy. Restructured power system often includes renewable energy sources. Increasing penetration of renewable resources in the electric grid is expected to have significant impact on transmission operation and planning. So, the power system is assumed to have an integrated wind generator in this analysis. The Power from renewable resources, like wind and solar, depends is highly stochastic in nature. The wind generator output power is assumed to have three levels of output, i.e., $100 \%, 75 \%$, and $50 \%$ of peak output power, and grows by 5\% yearly. Wind power generation is generally treated as a negative load in power system studies. This is to indicate their capability for delivering current meanwhile their voltage is imposed by the electrical system at the connection point [23]. 


\subsection{Main Objective Function}

The main objective function of FDs optimal allocation in restructured power system is formulated as follows:

\section{Minimize}

\section{TotalCost $=$}

$A I C_{\text {dev }}+\left(E B_{\text {withFACTS }}-E B_{\text {withoutFaCTS }}\right)$

where $\boldsymbol{A I} \boldsymbol{C}_{\boldsymbol{d e v}}$ is the annual devices investment cost, $\boldsymbol{E B}_{\text {with }}$ FACTS is the annual benefit of power system operation after instating FDs, and $\boldsymbol{E B}_{\text {without FACTS }}$ is the annual benefit of power system operation before instating FDs which is assumed already optimum and constant. The value of EB is negative, where it is the difference between generation costs and the revenue of loads. The first term in (4) is determined by number and capacities of installed FDs as explained in section 3.2. The second term in (4) depends on locations and capacities of installed devices as described in section 3.4.

\subsection{FACTS Devices Model and Investment Cost}

The range of cost of major FDs is presented in Siemens AG Database [19]. Based on this, a polynomial cost function of FDs derived and used for FACTS allocation study as used in [3, 11]. The investment costs of TCSC and SVC can be formulated as follows.

$$
\begin{gathered}
C_{T C S C}=0.0015 S_{T C S C}^{2}-0.713 S_{T C S C}+153.75 \\
C_{S V C}=0.0003 S_{S V C}^{2}-0.3051 S_{S V C}+127.38 \\
C_{U P F C}=0.0003 S_{U P F C}^{2}-0.2691 S_{U P F C}+188.22 \\
I C_{d e v}=\sum_{m \epsilon M} S_{T C S C, m} \times C_{T C S C, m}+ \\
\sum_{n \epsilon N} S_{S V C, n} \times C_{S V C, n}+\sum_{u \epsilon U} S_{U P F C, u} \times C_{U P F C, u}
\end{gathered}
$$

Constraint of FDs is given as follows:

$$
0 \leq c_{I x} \leq c_{I x, \max }
$$

Then, the following expression is used to convert the investment cost into annual term:

$$
A I C_{d e v}=I C_{d e v} \times \frac{i r(1+i r)^{L T}}{(1+i r)^{L T}-1}
$$

where ir is interest rate and $L T$ is lifetime of FDs.

\subsection{Market model}

In this study, a hybrid market model is considered. A voluntary central pool is the most likely arrangement that will emerge in practical restructured power system [10]. This pool will set the price of bilateral and/or multilateral transactions [24].The generation companies (GENCOs) submit bid curve (supply bid) to ISO and distribution companies (DISCOs) has the flexibility to submit either price elastic demand (with benefit bid curve) or fixed demand. The bilateral/multilateral transaction holders request transaction of power specifying the points of injection and points of extraction. They pay the energy charge based on difference in LMP at the points of injection and extraction. Based on the submitted bids by GENCO and DISCO, and considering the bilateral/multilateral transactions, the ISO solves the securityconstrained $\mathrm{OPF}$ to find the optimum dispatch [25].

\subsection{Operation Sub-problem}

The operation sub-problem objective function is to minimize the $\boldsymbol{E B}_{\text {with FACTS }}$. This benefit includes operating cost and load revenue under normal and contingency states. Each state benefit is separately computed by local OPF. It implies minimizing operating cost of each state by optimally utilizing the FDs with their installed capacities specified by the upper level sub-problem. In order to minimize the operating cost, each state is thus formulated as an OPF problem incorporating voltage stability criteria. The formulation of $\boldsymbol{E B}_{\text {with FACTS }}$ is given as follows:

$$
\begin{aligned}
& \text { Minimize } \\
& \text { E B Bith FACTS }=\sum_{t=1}^{T} \pi^{(0, t)} C^{(0, t)}+ \\
& \qquad \sum_{t=1}^{T} \sum_{k=1}^{K} \pi^{(k, t)} C^{(k, t)}
\end{aligned}
$$

where $C^{(0, t)}$ and $C^{(k, t)}$ are hourly operating benefit of normal state and contingency $k$ for load level $t$, respectively; $\pi^{(k, t)}$ is product of frequency and duration of contingency $k$ in a year for load level $t$. The 
duration of all contingency states and normal state is 8760 hours/year.

a)Normal State Sub-problem :The objective function during normal state is maximizing the social welfare. The social welfare is defined as the difference between generation cost and consumer benefit. It is formulated as follows:

Minimize

$\sum_{i=1}^{N w} C_{w i}\left(P_{w i}^{o}\right)$

$$
-\sum_{i=1}^{N l} B_{i}\left(P_{D i}^{o}\right)
$$

$$
C^{o}=\sum_{i=1}^{N g} C_{i}\left(P_{G i}^{o}\right)+
$$

Subject to:

Power balance equation for any node $i$, line flow, and voltage constrains:

$p\left(V_{i}^{o}, \theta_{i}^{o}, C^{o}\right)=P_{G i}^{o}+P_{W i}^{o}-P_{D i}^{o}+P_{G r, i}-$

$P_{D r, i}$

$q\left(V_{i}^{o}, \theta_{i}^{o}, C^{o}\right)=Q_{G i}^{o}+Q_{W i}^{o}-Q_{D i}^{o}+Q_{G r, i}-Q_{D r, i}$

(14)

$\mathrm{Q}_{\mathrm{Di}}^{\mathrm{o}}=\mathrm{P}_{\mathrm{Di}}^{\mathrm{o}} \times \tan \theta$

$\mathrm{P}_{\text {Gi min }} \leq \mathrm{P}_{\mathrm{Gi}}^{\mathrm{o}} \leq \mathrm{P}_{\text {Gi max }}$

$\mathrm{Q}_{\text {Gi max }}$

$\mathrm{P}_{\mathrm{Dimin}} \leq \mathrm{P}^{\mathrm{O}} \leq \mathrm{P}_{\mathrm{Dinax}}, \mathrm{Q}_{\mathrm{Dinin}} \leq \mathrm{Q}^{\circ} \leq$

$\mathrm{Q}_{\text {Di max }}$

$V_{i \min } \leq V_{i}^{o} \leq V_{i \max }, M A_{i j} \leq M A_{i j \max }$

bilateral/multilateral power balance:

$\sum_{i \in I_{G}} P_{G r, i}=\sum_{j \in J_{G}} P_{D r j}$

constraints to satisfy minimum loading margin:

$\bar{\lambda}^{0} \geq \lambda_{\min }$

demand and generation increase direction:

$$
\begin{array}{r}
\bar{P}_{G i}^{0}=P_{G i}^{0}\left(1+\bar{\lambda}^{0}+K_{s}\right) \\
\bar{P}_{D j}^{0}=P_{D j}^{0}\left(1+\bar{\lambda}^{0}\right) \\
\bar{Q}_{D j}^{0}=Q_{D j}^{0}\left(1+\bar{\lambda}^{0}\right)
\end{array}
$$

In this paper, it is assumed that, the generating units and loads submitted bids are the true marginal cost and the true marginal benefit respectively. Then, ISO clears the energy market based on those bids. Lagrange multiplier associated with real power balance equations obtained from OPF after installing of FDs will become market clearing price [3].

b) Contingency State Sub-problem: When a contingency state occurs, corrective actions such as FDs control (as a cost free means), generation re-scheduling, and load shedding (as non-cost free means) are utilized to avoid line overload, voltage instability and maintain load margin. Generation companies receive compensations as a result of changing the output power to nonoptimal value. If load shedding should be executed, demands will also be compensated for their interrupted load during contingency [26].

During contingency, the objective functions are maximizing social welfare and minimizing compensations due to generation re-scheduling and load shedding. Participating generators that increase their power output will not only receive profit from selling additional energy but also compensations for providing reserve power. Meanwhile, generators decreasing their power output will also obtain compensations for lost opportunity cost [3]. This function is formulated as follows:

$$
\begin{aligned}
& \text { Minimize } \quad C^{k}=\sum_{i=1}^{N g} C_{i}\left(P_{G i}^{k}\right)+\sum_{i=1}^{N w} C_{w i}\left(P_{w i}^{o}\right)- \\
& \sum_{j=1}^{N l} B_{j}\left(P_{D j}^{k}\right)+ \\
& \sum_{i=1}^{N g}\left(C_{G D}^{u p} \Delta P_{G i}^{u p, k}+C_{G D}^{\text {down }} \Delta P_{G i}^{\text {down }, k}\right) \\
& \quad+\sum_{i=1}^{N g}\left(C_{G D}^{u p} \Delta P_{G i}^{u p, k}+C_{G D}^{\text {down }} \Delta P_{G i}^{\text {down }, k}\right) \\
& \quad+\sum_{j=1}^{N l} C_{L S} \Delta P_{D j}^{\text {down }, k}
\end{aligned}
$$

In addition to the previous constraints this equation subject to:

constraints for generation re-scheduling and load shedding:

$$
\begin{gathered}
P_{G i}^{k}=P_{G i}^{0}+\Delta P_{G i}^{u p, k}-\Delta P_{G i}^{d o w n, k} \\
P_{D j}^{k}=P_{D j}^{0}-\Delta P_{D j}^{d o w n, k}
\end{gathered}
$$

$\Delta P_{G i}^{u p, k}, \Delta P_{G i}^{\text {down }, k}, \Delta P_{D j}^{\text {down }, k} \geq 0$

Constraints in (33) are intended to express coupling between normal and contingency states. Also, it is a way to ensure that compensations are always positive values. In case of contingency, demands have no option to increase their power exceeding the power demand determined in normal state.

\section{Solution algorithm}

The overall problem is formulated as a two-level hybrid large scale mixed integer nonlinear programming problem solved by hybrid

PSO-sequential quadratic 
programing (SQP) method. The upper level is solved using standard PSO. Locating FDs is a discrete problem. Determining devices capacities is a continuous problem. The outcomes of the upper level is passed to the lower level (operation sub-problem). This sub-problem is composed of multiple states. Each state is classified as a continuous problem. It is formulated as an OPF problem solved by SQP. Matpower version 4.1 [29] is used to solve each state problem. The lower level will provide the upper level with $\boldsymbol{E S C}_{\text {with Facts }}$ component of the fitness function.

The proposed solution algorithm can be described in the following steps and shown in the flowchart of fig. 4:

Step 1: Define line and bus data of the power system, contingency data (frequency and duration of each contingency), all operational constraints, and PSO parameters.

Step 2: Generate an initial population of particles with random positions and velocities representing location and size of FDs.

Step 3: Set iteration index ite $=0$.

Step 4: For each particle, update bus data (for SVC and shunt part of UPFC) and line data (for TCSC and series part of UPFC) based on its locations and setting values. Determine the load level and wind output power. Conduct OPF incorporating FDs, for normal and contingency states. Compute the operating cost and required devices capacities for each state.

Step 5: Calculate $\boldsymbol{E B}_{\text {with FACTS }}$ using operating costs of all states and their associated probabilities to occur. Calculate devices investment cost using (8).

Step 6: Evaluate the value of the fitness function (4). Check all the constraints. If any of the constraints is violated, a penalty term is applied. The calculated value of the fitness function is served as a fitness value of a particle.

Step 7: Compare the fitness value of each particle with the personal best, Pbest. If the fitness value is lower than Pbest, set this value as the current Pbest, and save the particle position corresponding to this Pbest value.

Step 8: Select the minimum value of Pbest from all particles to be the current global best, Gbest, and record the particle position corresponding to this Gbest value.

Step 9: Update the velocity and position of all particles.

Step 10: If the maximum number of iterations is reached, the particle associated with the current Gbest is the optimal solution. Otherwise, set ite $=i t e+1$ and return to Step 4 .

Step 11: End.

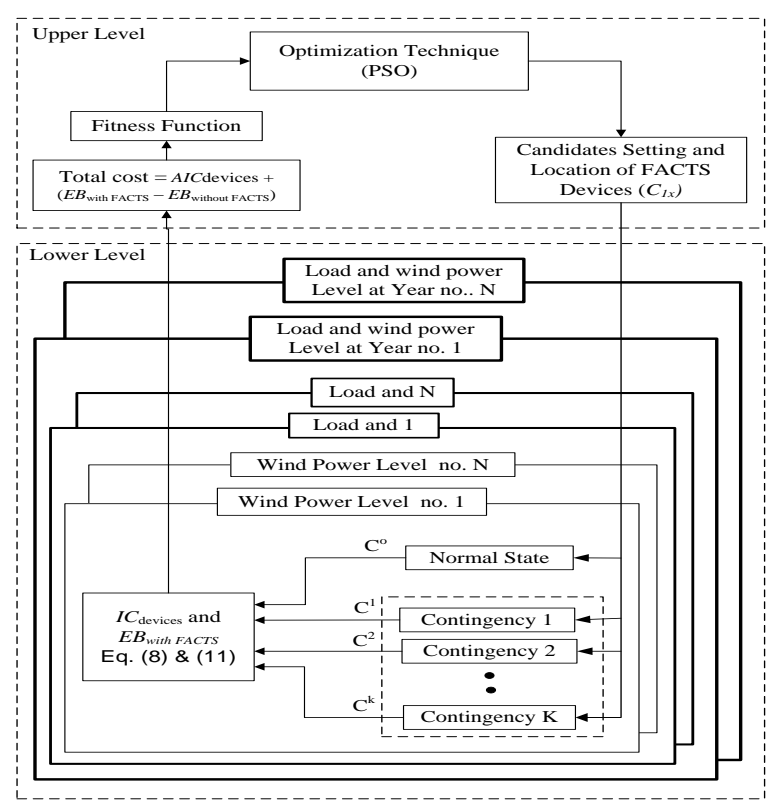

Fig. 4. Flowchart for proposed approach.

\section{Case studies and results}

The proposed solution algorithm is coded as one entity in MATLAB environment. The effectiveness of proposed approach will be illustrated using the IEEE 14-bus and 118-bus test systems. 


\subsection{IEEE 14-Bus System Case Study}

The modified IEEE 14 bus system is used to evaluate the proposed approach. Detailed data of generator, demand and lines limits are given in appendix 1 [29]. The system includes a wind generator at bus 8.There is also one multilateral transaction of 35MWbetween the seller $S$ at bus 6 and two buyers $\boldsymbol{B}$ at bus 9 and bus14. This transaction holder has requested ISO to provide transmission access to transmit power from bus 6 to bus 9 and bus14. It is assumed that the load at each bus including multilateral transaction grows with an annual rate of $5 \%$. The wind generator output power increases at an annual rate of $5 \%$ as well. The planning time period is taken as 10 years. The resulting optimal locations and capacities of FDs under normal operating conditions are presented in Table 1.

Table 1Optimal locations and capacities of FDs under normal state

\begin{tabular}{|l|c|c|c|c|c|c|}
\hline \multirow{3}{*}{ location } & \multicolumn{2}{|c|}{ TCSC (MVAR) } & \multicolumn{2}{c|}{$\begin{array}{c}\text { SVC } \\
\text { (MVAR) }\end{array}$} & \multicolumn{2}{c|}{ UPFC (MVAR) } \\
\cline { 2 - 7 } & \multicolumn{2}{|c}{} & & \multicolumn{2}{|c}{ series } & shunt \\
\hline Capacities & 0.6287 & Line 13-14 & Bus 9 & Bus 14 & Line 6-11 & Bus 11 \\
\hline
\end{tabular}

The required capacities of FDs under various contingency states are shown in Table 2. It is worthy noting the determined locations of FDs are the same for all contingency states. Also, it is observed that the highest FACTS setting occurs when the contingency line is 2-3.

Table 2 Optimal locations and capacities of FDs under contingency states

\begin{tabular}{|c|c|c|c|c|c|c|c|}
\hline \multirow{3}{*}{\multicolumn{2}{|c|}{$\begin{array}{c}\text { Contingency } \\
\text { line }\end{array}$}} & \multicolumn{6}{|c|}{ Required capacity (MVAR) } \\
\hline & & \multirow{2}{*}{\multicolumn{2}{|c|}{ TCSC }} & \multirow{2}{*}{\multicolumn{2}{|c|}{ SVC }} & \multicolumn{2}{|c|}{ UPFC } \\
\hline & & & & & & series & shunt \\
\hline From & To & Line 7-9 & Line 13-14 & Bus 9 & Bus 14 & Line6-11 & Bus 11 \\
\hline 1 & 2 & 0.1645 & 0.1792 & 28.34 & 5.45 & 2.90 & 28.02 \\
\hline 2 & 3 & 0.923 & 0.6666 & 29.12 & 27.88 & 2.67 & 28.88 \\
\hline 2 & 5 & 0.0079 & 0.2436 & \begin{tabular}{|l|}
0.0 \\
\end{tabular} & & 1.2086 & 0.0 \\
\hline 4 & 5 & 0.0067 & 0.0085 & 27.40 & 28.19 & 2.7589 & 28.95 \\
\hline 4 & 7 & 0.0715 & 0.2185 & 22.61 & 18.50 & 0.0352 & 26.05 \\
\hline 4 & 9 & 0.0367 & 0.0874 & 27.09 & 28.70 & 1.5549 & 29.15 \\
\hline 5 & 6 & 0.0 & 0.0024 & 1.80 & 0.0 & 2.6817 & 11.02 \\
\hline 10 & 11 & 0.073 & 0.2436 & 24.87 & 28.05 & 2.2817 & 29.05 \\
\hline 12 & 13 & 0.0001 & 0.2436 & 29.16 & 24.95 & 2.7653 & 28.95 \\
\hline 13 & 14 & 0.0131 & 0.0147 & 24.01 & 21.88 & 0.8151 & 28.67 \\
\hline
\end{tabular}

Tables 3 and 4 manifest the operating cost for each operation state before and after installing FD at $100 \%$ and $75 \%$ load levels, respectively. Outages of lines (2-5), (5-6) and (13-14) cannot be counterbalanced by re-setting of FD. Consequently, operating cost during those contingencies with FD is higher than the base case. Congestion relief and loss reduction contribute to the social welfare improvement under normal state.

Table 3 Average operating cost for $100 \%$ load level

\begin{tabular}{|c|c|c|c|c|c|c|}
\hline \multirow{3}{*}{ Open line } & \multicolumn{2}{|c|}{$\begin{array}{r}\text { Social welfare } \\
(\$ / \mathrm{h})\end{array}$} & \multicolumn{2}{|c|}{$\begin{array}{r}\text { Generation } \\
\text { re-scheduling } \\
\text { cost }(\$ / \mathrm{h})\end{array}$} & \multicolumn{2}{|c|}{$\begin{array}{r}\text { Load shedding cost } \\
(\$ / \mathrm{h})\end{array}$} \\
\cline { 2 - 7 } & $\begin{array}{r}\text { without } \\
\text { FD }\end{array}$ & $\begin{array}{r}\text { With } \\
\text { FD }\end{array}$ & $\begin{array}{r}\text { without } \\
\text { FD }\end{array}$ & $\begin{array}{r}\text { With } \\
\text { FD }\end{array}$ & $\begin{array}{r}\text { without } \\
\text { FD }\end{array}$ & With FD \\
\hline $\begin{array}{c}\text { Normal } \\
\text { state }\end{array}$ & -5947.5 & -8358.8 & 0 & 0 & 0 & 0 \\
\hline $1-2$ & -4372.9 & -8123.1 & 541.92 & 7.55 & 236270 & 0.0 \\
\hline $2-3$ & -5955.2 & -8414.2 & 343.84 & 6.77 & 167660 & 0.0 \\
\hline $2-5$ & -7807.1 & -7780.7 & 1409.7 & 469.4 & 485400 & 371140 \\
\hline $4-5$ & -5876 & -8293 & 125.53 & 7.78 & 131690 & 0.0 \\
\hline $4-7$ & -5719.8 & -8407.9 & 146.93 & 22.75 & 183440 & 0.0 \\
\hline $4-9$ & -6421.3 & -8306.2 & 134.22 & 16.93 & 93849 & 0.0 \\
\hline $5-6$ & -9038.2 & -6474 & 908.8 & 483.01 & 324500 & 19584 \\
\hline $10-11$ & -5916.5 & -8233.4 & 57.72 & 7.72 & 108930 & 0.0 \\
\hline $12-13$ & -5936.9 & -8279.2 & 19.58 & 7.71 & 32541 & 0.0 \\
\hline $13-14$ & -10899 & -8332.9 & 1282.6 & 7.61 & 445520 & 0.0 \\
\hline
\end{tabular}

Moreover, it is observed that load shedding can considerably be reduced in almost all of contingency states. Social welfare improvement during load level $75 \%$ is less significant than that during load level $100 \%$, but load shedding can be avoided for all contingency states. Generally, installing FACTS increases the delivered load and improves system security [5]-[10]. Generally, installing FACTS increases the delivered load and improves system security. So, it improves social welfare [510].

Table4 Average operating cost for $75 \%$ load level

\begin{tabular}{|c|c|c|c|c|c|c|}
\hline \multirow{2}{*}{$\begin{array}{c}\text { Open } \\
\text { line }\end{array}$} & \multicolumn{2}{|c|}{$\begin{array}{c}\text { Social welfare } \\
(\$ / \mathrm{h})\end{array}$} & \multicolumn{2}{c|}{$\begin{array}{c}\text { Generation } \\
\text { re-scheduling } \\
\text { cost }(\$ / \mathrm{h})\end{array}$} & \multicolumn{2}{c|}{$\begin{array}{c}\text { Load shedding } \\
\text { cost }(\$ / \mathrm{h})\end{array}$} \\
\cline { 2 - 7 } & $\begin{array}{c}\text { without } \\
\text { FD }\end{array}$ & With FD & $\begin{array}{c}\text { without } \\
\text { FD }\end{array}$ & With FD & $\begin{array}{c}\text { without } \\
\text { FD }\end{array}$ & With FD \\
\hline $\begin{array}{c}\text { Normal } \\
\text { state }\end{array}$ & -1861.8 & -1879.7 & 0 & 0 & 0 & 0 \\
\hline $1-2$ & -1792.3 & -1903.8 & 124.83 & 11.13 & 4547.6 & 0.0 \\
\hline $2-3$ & -1993.9 & -2005.4 & 58.76 & 5.79 & 2598.3 & 0.0 \\
\hline $2-5$ & -2178.1 & -2089.1 & 229.72 & 68.80 & 38103 & 2107 \\
\hline $4-5$ & -1878.9 & -1880 & 17.87 & 2.48 & 0.0 & 0.0 \\
\hline $4-7$ & -1797 & -1936.3 & 10.64 & 2.81 & 0.0 & 0.0 \\
\hline $4-9$ & -1873.6 & -1960.2 & 20.26 & 1.95 & 3099.3 & 0.0 \\
\hline $5-6$ & -2034.8 & -1969.8 & 362.78 & 42.12 & 45960 & 4155 \\
\hline $10-11$ & -1871.4 & -1875.1 & 20.70 & 1.626 & 0.0 & 0.0 \\
\hline $12-13$ & -1861.9 & -1865.4 & 0.64 & 0.16 & 0.0 & 0.0 \\
\hline $13-14$ & -1822.1 & -2074.9 & 79.41 & 3.73 & 24796 & 0.0 \\
\hline
\end{tabular}


Table 5 shows the average annual cost/benefit of system operation, without and with FD.

Table 5 Average annual cost of system operation.

\begin{tabular}{|c|c|}
\hline Items & Amount (\$/ year) \\
\hline Average annual EB with FDs & -43360491.32 \\
\hline Average annual EB without FDs & -28397356.98 \\
\hline Average annual benefit in EB due to FDs & 14963134.34 \\
\hline Average annual cost of FDs & 1993216.6 \\
\hline Net increase in social welfare due to FDs & 12969917.74 \\
\hline
\end{tabular}

Fig.5 gives the uninterruptible average loads (over 10 years) at individual buses without and with FD. It is evident that FD utilization improves loadability as it increases amount of uninterruptible average loads. Shed part of interruptible average load at almost all buses is eliminated except very small amount of interruptible load at bus 9 and bus10. It is noted that the shed part of all interruptible loads is zero up to the $5^{\text {th }}$ year of the planning period. Starting from the $6^{\text {th }}$ year, a small amount of interruptible loads is shed at buses 9 and 10 . This is due to that the power system is highly stressed by increasing loads. So, line congestion and impermissible voltage drop cannot be eliminated without load shedding under this very high load condition.

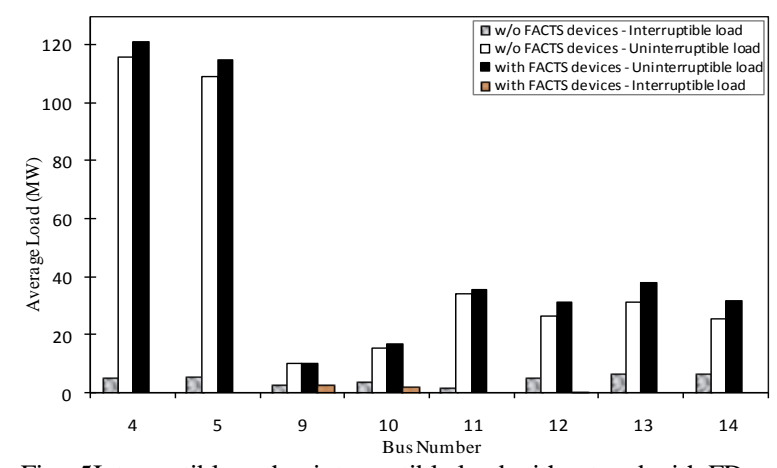

Fig. 5Interruptible and uninterruptible load without and with FDs (load level 100\%).

Figs. 6 and 7 describe the detailed load shedding and generation re-scheduling without and with FD. Load shedding and generation re-scheduling are significantly reduced by optimal installation of FD. Load shedding is eliminated under most of contingency states. However, under critical contingencies at lines (2-5) and (5-6), the FD cannot avoid a small amount of load curtailment. Power generation re- scheduling also considerably decreases under all contingency cases due to optimal installation of FD.

Fig. 8 gives the relation between load growth and years. It can be seen that, the system is always able to accommodate the monotonic yearly increase in the load with the favor of optimally installing FDs. There is no need to expensive transmission and/or generation expansions. On the other hand, without FDs, the system can only accommodate the monotonic yearly increase up to the $5^{\text {th }}$ year of the planning period. Then, expensive transmission and/or generation expansions are inevitable.

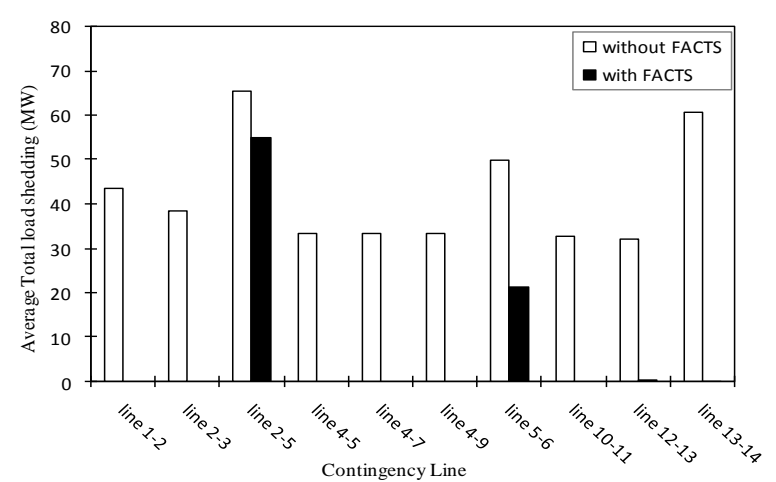

Fig. 6 Average load shedding under various contingencies (load level $100 \%$ )

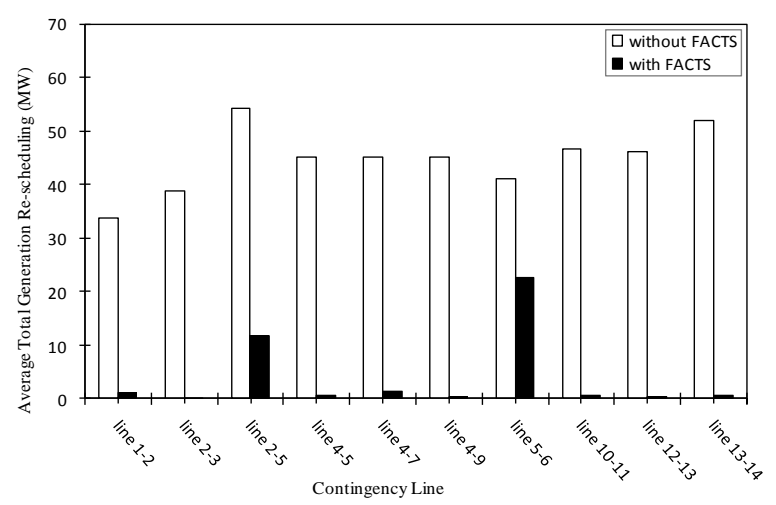

Fig. 7 Average total generation re-scheduling under various contingencies (load level 100\%)

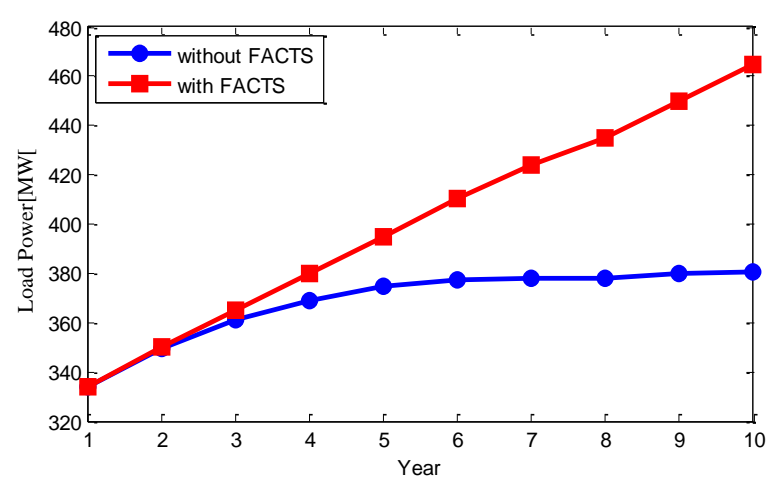

Fig. 8 Average total load for each year (load level 100\%) 
Fig. 9 presents the relation between social welfare and years. It can be remarked that the social welfare from the system is much higher owing to installing FDs. This is attributed to the fact that FACTS improves the economics of system operation and greatly increases its load ability.

Fig. 10 shows the bus voltage profile with and without FDs. It can be seen that, when FDs properly installed in the system, the voltage of all buses are improved. This leads to increase the voltage stability. Fig. 11 presents the power flow in TL. From this fig. it can be show that, after installing of FACTS devices, the power flow in most TLs increase. This leads to increasing of the system load ability due to congestion management of TLs.

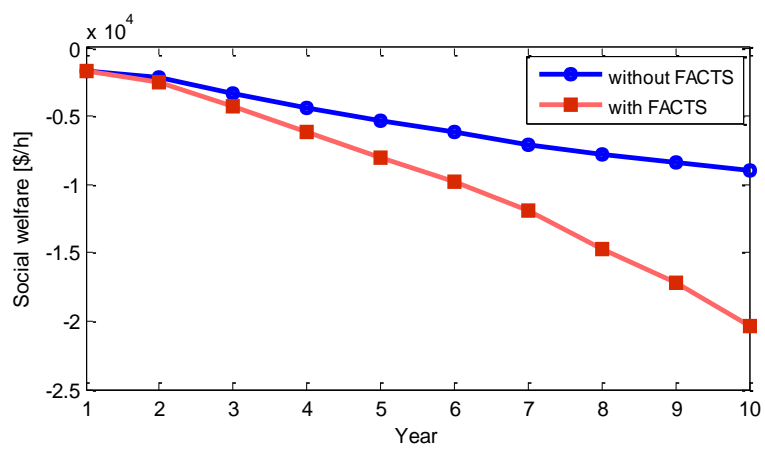

Fig. 9 Average social welfare for each year (load level 100\%)

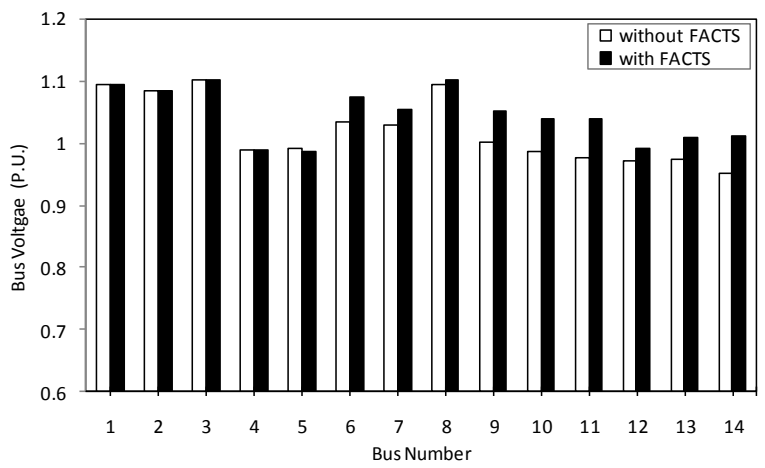

Fig. 10 Bus voltage (at load level 100\% and wind power level $100 \%)$ )

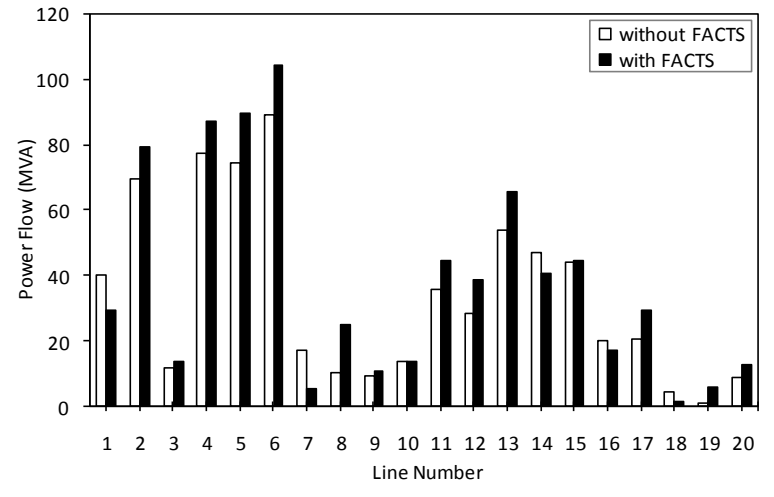

Fig. 11 Line power flow (at load level $100 \%$ and wind power level 100\%))

\subsection{The effect of wind generator}

In this section, the effect of wind generator in the normal state operation of the system will be discussed. There are four cases of possibilities for the operation of the system as follows:

$i$. The system contain wind generator with FACTS devices: in this case the average social welfare is $8358.8 \$ / \mathrm{h}$, and the lower voltage in the system in the tenth year is $0.9865 \mathrm{~V}$ and occurs at bus 5 . The congestion not occurs of any line.

ii. The system contain wind generator without FACTS devices: in this case the average social welfare is $5947.5 \$ / \mathrm{h}$, and the lower voltage in the system in the tenth year is $0.95 \mathrm{~V}$ and occurs at bus 14. The congestion occurs in the line (4-5) and (10-11).

iii. The system not contain wind generator with FACTS devices: in this case the average social welfare is $7454.9 \$ / \mathrm{h}$, and the lower voltage in the system in the tenth year is $0.9999 \mathrm{~V}$ and occurs at bus 5 . The congestion occurs in the line (10-11) and (4-5).

iv. The system not contain wind generator without FACTS devices: in this case the average social welfare is $5485.7 \$ / \mathrm{h}$, and the lower voltage in the system in the tenth year is $0.95 \mathrm{~V}$ and occurs at bus 14 . The congestion occurs in the line (10-11).

From the above it can be concluded that the presence of wind generator leads to increase of social welfare especially with FD. Also, it can cause congestion in some lines. Inclusion of FD 
in the power system can significantly mitigate this congestion.

The integration of renewable resources into the operation of power systems very necessary, where reduce operating costs, reduce global warming, and increase social welfare. With increasing steps of load duration curve and the penetration level of wind generators, we approach to the real configuration of the restructured power system. But, calculation time increase, especially with larger system.

\subsection{IEEE 118-Bus System Case Study}

In order to show the applicability of the proposed algorithm in large scale system, a modified IEEE118 bus test system is used. The system consists of 54 generator buses, 99 loads and 186 branches (TLs plus transformers). The bus data and line data values are taken from [29]. The system contains two wind generators at bus 37 and 38. Simulations are carried out for optimal location and capacity for multi-type FACTS devices. It is assumed that there are 25 FACTS devices available for the system (this number was chosen because the improvement of system loadability not improved after this number) [11].

Table 6 shows the suitable location and size of multi-type FACTS devices. By installing those devices, the annual cost saving is $\$ 10272138$ for normal operation state at $100 \%$ of load level.

Table 6: Suitable Locations and Capacities of FDs for IEEE 118Bus System

\begin{tabular}{|l|l|l|l|l|l|l|l|}
\hline \multicolumn{3}{|l|}{ TCSC } & \multicolumn{2}{l|}{ SVC } & \multicolumn{2}{l|}{ UPFC } \\
\hline $\begin{array}{l}\text { Loca- } \\
\text { tion }\end{array}$ & $\begin{array}{l}\text { apacity } \\
\text { (MVAR) }\end{array}$ & $\begin{array}{l}\text { Loca- } \\
\text { tion }\end{array}$ & $\begin{array}{l}\text { Capacity } \\
\text { (MVAR) }\end{array}$ & $\begin{array}{l}\text { Series } \\
\text { Location }\end{array}$ & $\begin{array}{l}\text { Capacity } \\
\text { (MVAR) }\end{array}$ & $\begin{array}{l}\text { Shunt } \\
\text { Location }\end{array}$ & $\begin{array}{l}\text { Capacity } \\
\text { (MVAR) }\end{array}$ \\
\hline $37-39$ & -1.5895 & 94 & 1.11 & $86-87$ & -0.2022 & 87 & 18.44 \\
\hline $18-19$ & -0.1013 & 109 & 1.77 & $38-65$ & -9.8024 & 65 & 13.75 \\
\hline $103-110$ & -0.3957 & 95 & 12.86 & $76-118$ & -0.0134 & 118 & 6.04 \\
\hline $33-37$ & -0.6707 & 10 & 21.64 & $38-37$ & -8.193 & 37 & 15.22 \\
\hline $55-56$ & -0.0144 & 50 & 2.3335 & $35-36$ & -0.0066 & 36 & 7.77 \\
\hline $15-19$ & -0.0029 & 92 & 18.46 & $75-77$ & -0.0963 & 77 & 17.82 \\
\hline $64-65$ & -0.9441 & 107 & 13.76 & $49-66$ & -7.8394 & 66 & 1.51 \\
\hline $82-96$ & -0.1749 & 81 & 11.25 & $95-96$ & -0.0913 & 96 & 24.12 \\
\hline $5-11$ & -5.2589 & 21 & 5.81 & $14-15$ & -0.0014 & 15 & 9.75 \\
\hline $91-92$ & -0.0507 & 73 & 5.18 & $39-40$ & -0.0065 & 40 & 22.38 \\
\hline
\end{tabular}

\section{Conclusion}

This paper presents an approach to optimally allocate multiple FACTS devices for congestion management and voltage stability in deregulated electricity market environment. The proposed approach is based on a comprehensive cost model that considers the annual cost of FACTS devices, operation cost, and customer benefit. The effect of wind generation and load growth are addressed.

The task is formulated as a two-level mixed-integer nonlinear optimization problem. The annual net cost is taken as the objective function. Bus voltage limits, line flow limits, generator capacity limits are the main constraints. Hybrid Particle-swarm and sequential quadratic programmingbased OPF are employed to solve the optimization problem. The impacts of the optimally allocated FACTS devices includes increasing of social welfare and reducing of the compensation paid to market participants due to generation rescheduling and load shedding.

\section{Appendix}

Setting of parameters and constants used in simulation are given as follows.

1. The MVA limits of Transmission network are three times of base case line flow. The voltage limits is 0.95 to 1.1 $\mathrm{pu}$, and all loads have constant power factor of 0.9 .

2. Number of PSO particles is 40 and number of iterations is 100. Parameters $c_{1}, c_{2}, \omega_{\max }$ and $\omega_{\min }$ used in PSO are 1 , $1,0.9$, and 0.4 , respectively.

3. Maximum equivalent reactance of TCSC is assumed between $-0.7 \quad X_{\text {line }}$ (capacitive) and $0.2 X_{\text {line }}$ (inductive), while maximum installed capacity of SVC is $0.3 \mathrm{pu}$. The capacity range for UPFC is the same as for TCSC and SVC.

4. Interest rate and life time of devices are assumed to be 0.04 and 15 years, respectively.

5. $C_{G D}^{u p}$ and $C_{G D}^{\text {down }}$ are 0.4 of power price in normal state. Meanwhile, $C_{L S}$ is $\$ 10838$ per MWh-curtailed load [3]. 
6. The duration of load levels $100 \%, 75 \%$, and $50 \%$ are assumed to be 12,6 , and 6 $\mathrm{h}$ per day, respectively. The duration of various contingencies is 240 hour per year.

Table 7 Generator data

\begin{tabular}{|c|c|c|c|c|c|c|c|c|}
\hline \multirow{2}{*}{ No. } & Bus & \multicolumn{2}{|c|}{ P(MW) } & \multicolumn{2}{|c|}{ Q(MVAR) } & \multicolumn{3}{c|}{ Cost coefficient } \\
\cline { 3 - 9 } & NO. & Max & Min & Max & Min & $\mathrm{C}_{2}$ & $\mathrm{C}_{1}$ & $\mathrm{C}_{\mathrm{o}}$ \\
\hline 1 & 1 & 100 & 0.0 & 40 & 0.0 & 0.245 & 10 & 0.0 \\
\hline 2 & 2 & 500 & 0.0 & 50 & 0.0 & 0.351 & 10 & 0.0 \\
\hline 3 & 3 & 500 & 0.0 & 50 & 0.0 & 0.389 & 10 & 0.0 \\
\hline 4 & 6 & 100 & 0.0 & 50 & 0.0 & 0.372 & 10 & 0.0 \\
\hline 5 & 8 & 0.0 & 0.0 & 25 & 0.0 & - & - & - \\
\hline
\end{tabular}

Table 8 Pool demand data

\begin{tabular}{|c|c|c|c|c|c|c|c|}
\hline \multirow{2}{*}{ No. } & \multirow{2}{*}{$\begin{array}{c}\text { Bus } \\
\text { No. }\end{array}$} & \multicolumn{2}{|c|}{$\mathrm{P}(\mathrm{MW})$} & \multirow{2}{*}{$\begin{array}{c}\text { Maximum } \\
\text { interruptible }\end{array}$} & \multicolumn{2}{|c|}{ Cost coefficient } \\
\cline { 3 - 4 } \cline { 7 - 8 } & & Min & Max & load (MW) & C2 & C1 & Co \\
\hline 1 & 4 & 95 & 142.5 & 47.5 & -0.15 & 100 & 0.0 \\
\hline 2 & 5 & 90 & 135 & 45 & -0.15 & 100 & 0.0 \\
\hline 3 & 10 & 15 & 22.5 & 7.5 & -0.15 & 100 & 0.0 \\
\hline 4 & 11 & 28 & 42 & 14 & -0.18 & 120 & 0.0 \\
\hline 5 & 12 & 25 & 37.5 & 12.5 & -0.18 & 120 & 0.0 \\
\hline 6 & 13 & 30 & 45 & 15 & -0.18 & 120 & 0.0 \\
\hline
\end{tabular}

Table 9 Multilateral contract data

\begin{tabular}{|c|c|c|c|c|c|c|c|}
\hline \multirow{2}{*}{ No. } & \multirow{2}{*}{$\begin{array}{c}\text { Bus } \\
\text { No. }\end{array}$} & Type & Min & $\begin{array}{c}\text { Annual } \\
\text { increase rate }\end{array}$ & C2 & C1 & Co \\
\hline 1 & 6 & seller & 35 & $5 \%$ & -0.15 & 100 & 0.0 \\
\hline 2 & 9 & Buyer 1 & 10 & $5 \%$ & -0.15 & 100 & 0.0 \\
\hline 3 & 14 & Buyer 2 & 25 & $5 \%$ & -0.15 & 100 & 0.0 \\
\hline
\end{tabular}

7. The peak output power of wind generator at bus 8 is $20 \mathrm{MW}$, and the duration of output levels $100 \%, 75 \%$, and $50 \%$ are assumed to be one-third of each load interval as shown in fig. 12 . The cost coefficient $C_{w i}$ is $\$ 20$ per MWh of output power.

Data of generators and demands are given in Tables 7, 8 and 9 respectively.

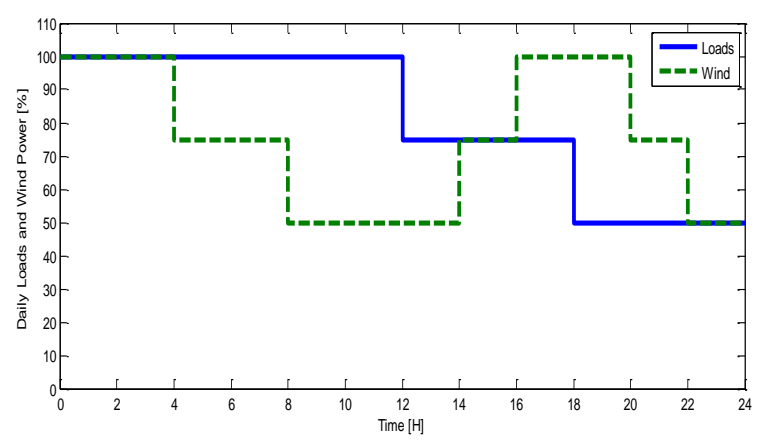

Fig.12. Daily variation of loads and wind availability.

\section{References}

[1] A. Vishwakarma, and D. Sahu,
"Efficient Voltage Regulation in Three Phase A.C. Transmission Lines Using Static VAR Compensator, "International Journal of Advanced Research in Electrical, Electronics and Instrumentation Engineering, vol. 2, no. 5, pp. 1773-1780, May 2013.

[2] M. Shahidehpour, H. Yatim, and Z.Li, Market Operations in Electric Power Systems. New York, Wiley, 2002.

[3] R. Wibowo, N. Yorino, M. Eghbal, Y. Zoka and Y. Sasaki, "FACTS Devices Allocation With Control Coordination Considering Congestion Relief and Voltage Stability," IEEE Trans. Power Syst., Vol. 26,No.4, pp.2302-2310,Nov. 2011.

[4] N. Hingoranl and L. Gyugyi, Understanding FACTS-Concepts and Technology of Flexible $A C$ Transmission Systems, New York, Wiley,2000.

[5] I. Kheirizad, A. Mohammadi andM. Varahram, "A Novel Algorithm for Optimal Location of FACTS Devices in Power System Planning," Journal of Electrical Engineering \& Technology, vol. 3, no. 2, pp. 177-183, 2008.

[6] S. Singh and A. David, "Optimal Location of FACTS Devices for Congestion Management," Elect. Power Syst. Res., vol. 58, no.2, pp. 7179,2001.

[7] Y. Luand A. Abur, "Static Security Enhancement Via Optimal Utilization of Thyristor-Controlled Series Capacitor," IEEE Trans. Power Syst., vol. 17,no.2, pp.324-329,May2002.

[8] J. Singh, S. Singh and S. Srivastava, "An Approach for Optimal Placement of Static VAr Compensators Based on Reactive Power Spot Price," IEEE Trans. on Power Systems, vol. 22,no. 4, pp. 2021-2029, 2007.

[9] N. Acharya and N. Mithulananthan, "Locating Series FACTS Devices for Congestion Management in Deregulated Electricity Markets," Elect. Power Syst. Res., vol. 77, no.3-4,pp. 352-360, Mar.2007. 
10] N. Acharya and N. Mithulananthan, "A Proposal for Investment Recovery of FACTS Devices in Deregulated Electricity Markets," Elect. Power Syst. Res., vol. 77, no.6,pp. 695-703,Apr. 2007.

[11]S. Gerbex, R. Cherkaoui, and A. Germond, "Optimal Location of MultiType FACTS Devices in Power System by Means of Genetic Algorithm," IEEE Trans. Power Syst., vol. 16, no. 3, pp. 537-544,Aug. 2001.

[12]N. Yorino, E. El-Araby, H. Sasaki, and S. Harada, "A New Formulation for FACTS Allocation for Security Enhancement Against Voltage Collapse," IEEE Trans. Power Syst., vol. 18, no. 1, pp. 3-10, Feb. 2003.

[13]R. Minguez, F.Milano, R. Minano, and A. Conejo, "Optimal Network Placement of SVC Devices," IEEE Trans. Power Syst., vol. 22, no. 4, pp. 1851-1860, Nov.2007.

[14] M. Eghbal, N. Yorino, E. El-Araby, and Y. Zoka, "Multi-Load Level Reactive Power Planning Considering Slow and Fast VAR Devices by Means of Particle Swarm Optimization," IET Trans. Gen., Transm., Distrib., vol. 2 ,no. 5, pp. 743-751, Sep. 2008.

[15]M. Saravanan, S. Mary, R. Slochanal, P. Venkatesh, J. Prince, and S. Abraham, "Application of Particle Swarm Optimization Technique for Optimal Location of FACTS Devices Considering Cost of Installation and System Loadability," Elect. Power Syst. Res., vol. 77, no. 3-4, pp. 276-283, Mar. 2007.

[16]R. Benabid, M. Boudour, and M. Abido, "Optimal Location and Setting of SVC and TCSC Devices using NonDominated Sorting Particle Swarm Optimization," Elect. Power Syst. Res., vol. 79, no. 12, pp. 1668-1677, Dec. 2009.

[17]F. Milano, "An Open Source Power System Analysis Toolbox," IEEE Trans. On Power Systems, vol. 20, no.3, pp. 1199-1206, Aug. 2005.
[18]S. Reddy, M. Kumari, and M. Sydulu, “ Congestion Management in Deregulated Power System by Optimal Choice and Allocation of FACTS Controllers Using Multi-Objective Genetic Algorithm," Trans. and Distrib Conf. and Exp., IEEE PES, New Orleans, LA, USA, 19-22 Apr. 2010.

[19]K. Habur, D. O'Leary "FACTS for Cost Effective and Reliable Transmission of Electrical Energy", Available www.worldbank.org/html/fpd/em/trans mission/facts_siemens.pdf.

[20]L. Cai, I. Erlich and G. Stamtsis, "Optimal Choice and Allocation of FACTS Devices in Deregulated Electricity Market using Genetic Algorithms," in IEEE PES General Meeting, pp. 201-207, Aug. 22-27, 2004.

[21] M. Karami, N. Mariun, and M. Ab Kadir, "On the Application of Heuristic Method and Saddle-Node Bifurcation for Optimal Placement of FACTS Devices in Power System," International Review of Electrical Engineering (I.R.E.E.), vol. 6, no. 7, pp. 3185-3159, Nov. 2011.

[22]N. Abdullah, I. Musirin, and M. Othman, " Transmission Loss Minimization Using Evolutionary Programming Considering UPFC Installation Cost," International Review of Electrical Engineering (I.R.E.E.), vol. 5, no. 3, Jun. 2010.

[23]M. Pincetic, G. Wang, A. Kowli, and H. Painemal, "Emerging Issues due to the Integration of Wind Power in Competitive Electricity Markets," Power and Energy Conference at Illinois (PECI), pp. 45-50, 12-13 Feb. 2010.

24] A. Exposito, A. Conejo, and C. Canizares, "Electric Energy Systems: Analysis and Operation," CRC Press, Boca Raton, Florida, 2009.

[25]N. Acharya, and N. Mithulananthan, "Influence of TCSC on Congestion and Spot Price in Electricity Market With 
Bilateral Contract," Elect. Power Syst. Res., vol. 77, no. 8, pp. 1010-1018, June 2007.

[26]R. Wibowo, N. Yorino, Y. Zoka, Y. Sasaki, and M. Eghbal, " FACTS Allocation Based on Expected Security Cost by Means of Hybrid PSO," Power and Energy Engineering Conference (APPEEC), pp. 1-4, Chengdu, 28-31 Mar. 2010.

[27] J. Kennedy and R. Eberhart, "Particle Swarm Optimization," in Proc. IEEE Int. Conf. Neural Networks, Australia, pp. 1942-1948, 1995.

[28] J. Park, K. Lee, J. Shin, and K. Lee, “A Particle Swarm Optimization for Economic Dispatch with Nonsmooth Cost Function," IEEE Trans. On Power Systems, vol. 20, no.1, pp. 34-42, Feb. 2005.

[29]R. Zimmermann and D. Gan, "Matpower: a Matlab Power System Simulation Package," User's Manual Version 4.1, Dec. 2011. 